\title{
Photosynthetic properties and biochemical metabolism of Cucurbita moschata genotypes following infection with powdery mildew
}

\author{
Bi-Hua Chen ${ }^{1,2} \cdot$ Wei-Li Guo ${ }^{1,2} \cdot$ He-Lian Yang ${ }^{1,2} \cdot$ Qing-Fei Li ${ }^{1,2} \cdot$ Jun-Guo Zhou ${ }^{1,2} \cdot$ Xin-Zheng Li ${ }^{1,2}$
}

Received: 22 August 2019 / Accepted: 24 April 2020 / Published online: 18 June 2020

(C) The Author(s) 2020

\begin{abstract}
Powdery mildew (PM) is one of the most important fungal diseases in Cucurbita moschata (pumpkin) cultivation. This experiment was conducted to shed light on the physiological mechanisms of PM resistance in pumpkin cultivars. PM pathogen was inoculated on pumpkin seedlings, PM-susceptible genotype (JJJD) and PM-resistant genotype (inbred line 112-2) to study the PM-fungal growth, plant photosynthetic and biochemical parameters with different intervals of time. The disease index and pathogen growth observed for the PM-infected 112-2 seedlings were milder than those observed for the JJJD seedlings. The net photosynthetic rate $(\mathrm{Pn})$, stomatal conductance (gs) and transpiration rate (Tr) were reduced for both the PM-infected genotypes, while the internal $\mathrm{CO}_{2}$ concentration $(\mathrm{Ci})$ increased in comparison with the non-infected controls. PM pathogen inoculation impaired the photosynthetic performance in seedlings of both genotypes and this was largely associated with stomatal closure. In comparison with the non-infected controls, the superoxide dismutase (SOD) and $\beta$-1,3-glucanase activities were reduced for both the PM-infected genotypes, while the peroxidase (POD) and phenylalanine ammonia lyase (PAL) activities were increased. The catalase (CAT) activity was reduced in the 112-2 genotype and increased in the JJJD genotype after PM pathogen inoculation. Together, our data show that PM resistance in pumpkin seedlings is associated with the maintenance of photosynthetic performance and the regulation of defense-related enzyme activities .
\end{abstract}

Keywords Cucurbita moschata $\cdot$ Powdery mildew $\cdot$ Photosynthetic index $\cdot$ Defense-related enzyme $\cdot$ Biochemical metabolism

\section{Introduction}

The genus Cucurbita is composed of several species, including those that are cultivated Cucurbita moschata Duch., Cucurbita pepo L. and Cucurbita maxima Duch. and several wild species. C. moschata is an economically important species that is cultivated worldwide and has high productivity. Pumpkins are valued for their fruit and seeds and are rich in vitamins, amino acids, flavonoids, phenolics and carbohydrates. Pumpkins also have important medicinal properties,

Wei-Li Guo

guoweili1226@sina.com

Bi-Hua Chen

183363468@qq.com

1 School of Horticulture Landscape Architecture, Henan Institute of Science and Technology, Xin Xiang 453003, China

2 Henan Province Engineering Research Center of Horticultural Plant Resource Utilization and Germplasm Enhancement, Xinxiang 453003, China including antidiabetic, antioxidant, anticarcinogenic and anti-inflammatory activities (Yadav et al. 2010). Cucurbit powdery mildew (PM), mainly caused by Podosphaera xanthii ( $P$. xanthii) (formerly Sphaerotheca fuliginea) (Perez-Garcia et al. 2009; Fukino et al. 2013), is a serious biotrophic pathogen disease in field and greenhouse cucurbit crops worldwide. In pumpkin, PM mainly affects the leaves, with chlorosis and yellowish spots appearing in the early stages of the disease that gradually expand to spread white powdery matter across the whole leaves. PM substantially reduces pumpkin photosynthesis and causes premature desiccation of the leaves that together decrease the quality and marketability of the fruits.

Photosynthesis is a critical process for crop growth and performance, and it can be dramatically impaired when leaves are infected by foliar pathogens (Berger et al. 2007). Pathogen infection reduces the photosynthetic rate, which is usually associated with damage to the photosynthetic apparatus and increased excitation energy that exceeds that required for photosynthetic metabolism. These effects ultimately lead to the reduction of molecular oxygen and formation of reactive 
oxygen species (ROS); in particular, $\mathrm{H}_{2} \mathrm{O}_{2}$ (Bassanezi et al. 2002; Kumudini et al. 2008; Behr et al. 2010; Iqbal et al. 2012). $\mathrm{ROS}$ and $\mathrm{H}_{2} \mathrm{O}_{2}$ have fundamental roles in plant defense mechanisms, and act directly as antimicrobial/antiviral agents and indirectly by inducing the hypersensitive response (HR). This leads to expression of $\beta-1,3$-glucanases, and pathogenesis-related (PR) proteins that are encoded by systemic acquired resistance (SAR) genes (Seung and Hwang 1996) and strengthening of the plant cell walls via crosslinking of glycoproteins (Jones and Dangl 2006; Torres 2010). Therefore, examining the leaf gas exchange parameters: net photosynthetic rate $(\mathrm{Pn})$, stomatal conductance to water vapor $(\mathrm{gs})$, transpiration rate $(\mathrm{Tr})$ and internal $\mathrm{CO}_{2}$ concentration $(\mathrm{Ci})$ can be used to fully assess the photosynthetic performance of plants under pathogen infection. These properties can be used to provide insights into the mechanisms underlying plant-pathogen interactions (Rolfe and Scholes 2010).

ROS production is an important plant defense strategy against pathogen infection (Magbanua et al. 2007). However, an imbalance between ROS production and removal can lead to ROS accumulation and damage to the host tissue (Lima et al. 2002; Scandalios 2011). To maintain homeostatic control of ROS, plants have antioxidative enzymes and metabolites, including superoxide dismutase (SOD), which catalyzes the dismutation of $\mathrm{O}^{2-}$ to $\mathrm{H}_{2} \mathrm{O}_{2}$ and $\mathrm{O}_{2}$; catalase (CAT), which dismutates $\mathrm{H}_{2} \mathrm{O}_{2}$ to $\mathrm{O}_{2}$ and $\mathrm{H}_{2} \mathrm{O}$; and guaiacol peroxidase (POD), which reduces the $\mathrm{H}_{2} \mathrm{O}_{2}$ produced by SOD to $\mathrm{H}_{2} \mathrm{O}$ and is the key enzyme involved in $\mathrm{H}_{2} \mathrm{O}_{2}$ scavenging. POD is activated by overproduction of ROS and is an oxido-reductive enzyme that participates in the reinforcement of the cell wall through suberization, lignification and crosslinking. It also activates defense genes in response to pathogens (Borden and Higgins 2002). In addition, phenylalanine ammonia lyase (PAL) catalyzes the first committed step in the phenylpropanoid pathway, which is believed to play a critical role in regulating lignin accumulation in plants.

In this study we aimed to shed light on the mechanisms of resistance to PM. We compared the PM-susceptible "Jiujiangjiaoding" genotype (JJJD) with PM-resistant inbred line "112-2". For each genotype we measured the PM-infectivity, photosynthetic parameters and defense-related enzyme activities of both genotypes following PM pathogen inoculation.

\section{Materials and methods}

\section{Plant materials and PM pathogen inoculation}

Two genotypes of $C$. moschata were tested in this study, inbred line 112-2 and cultivar JJJD, which have been shown to be resistant and susceptible to PM, respectively. Seed for each of these genotypes were provided by the Henan Institute of Science and Technology, Xinxiang, Henan, China (Zhou et al. 2010). Line 112-2 has been inbred through eight consecutive generations of self-pollination and exhibited high PM resistance in an 8-year outdoor field observation study. After at least $80 \%$ of the seeds had germinated, they were placed in 9-cm-deep plastic pots containing a 1:1 mixture of soil and peat in a growth chamber under long-day conditions $(15 \mathrm{~h}$ of $100 \mu \mathrm{mol} \mathrm{m} \mathrm{m}^{-2} \mathrm{~s}^{-2}$ photosynthetically active radiation at $28^{\circ} \mathrm{C}$ and $9 \mathrm{~h}$ dark at $18^{\circ} \mathrm{C}$ ) to grow for 4 weeks before pathogen inoculation.

$P$. xanthii conidia were collected from naturally infected pumpkin leaves in a local greenhouse. A spore suspension at $10^{6}$ spores per $\mathrm{mL}$ was made by soaking heavily infected leaves in tap water containing $0.01 \%$ Tween-20. When the seedlings had formed 2-3 fully expanded leaves (at approximately 4 weeks), the pots were divided into four groups. The four groups included the two control groups, named 112-2CK and JJJD-CK, and the two PM treatment groups, named 112-2-PM and JJJD-PM. The control groups were sprayed with distilled water and the PM treatment groups were sprayed with the spore suspension in the morning between 8:00 and 9:00 am until the surfaces of the seedlings were completely wet. Immediately after inoculation, the seedlings were transferred to a growth chamber as described. The control plants were kept in a separate growth chamber. The treatments were used as the following analysis and arranged in a randomized complete block design that consisted of four independent biological replicates.

\section{Determination of severity of PM infection}

At 6 days post inoculation (dpi), disease severity of the seedlings were scored on a 1 to 9 scale and calculated as a weighted average for each of these entries as described by Thomas et al. (2005). Circular disks of $2.5-\mathrm{cm}$ diameter were excised from the young upper leaves of each seedling and placed in a sterile Petri dish lined with moist blotting paper. The leaf disks were inoculated by adding $10 \mu \mathrm{L}$ of the spore suspension $\left(10^{6}\right.$ spores $\left./ \mathrm{mL}\right)$ to the adaxial surface of the disk. Disease severity of the leaf disks were calculated as $[(5 A+4 B+3 C+2 D+E) / 5 F] \times 100$ according to Ishii et al. (2001). Mildew development on each leaf disk was recorded, using the following scale: $0=$ no visible mildew development, $1=0$ to $5 \%, 2=6$ to $25 \%, 3=26$ to $50 \%, 4=51$ to $75 \%$, and $5=>76 \%$ of disk surface covered with mildew, where A, B, $\mathrm{C}, \mathrm{D}$, and $\mathrm{E}$ were the number of leaf disks corresponding to the scales, 5, 4, 3,2, and 1, respectively, and $\mathrm{F}$ was the total number of leaf disks assessed.

\section{Microscopic examination of PM pathogen infection}

The third leaves (three leaves from each treatment per replication) of inoculated and control seedlings of both genotypes 
were excised at $12,24,48,72,96$ and $120 \mathrm{~h}$ of pathogen inoculation (hpi) and processed for microscopy observation Guo et al. (2018).

\section{Photosynthetic parameters assay}

Leaf gas exchange was measured using a Li-6400 Portable Photosynthesis System (Li-Cor, USA). The Pn, gs, Ci and $\mathrm{Tr}$ were measured on the third leaf between 8:00 and 11:00 am. The irradiance level was set at $600 \mu \mathrm{mol}$ photons $\mathrm{m}^{-2} \mathrm{~s}^{-1}$ and all measurements were performed at ambient temperature $\left(25^{\circ} \mathrm{C}\right)$ at $1,2,4,6,8,10,12$ and $14 \mathrm{dpi}$.

\section{Antioxidant enzyme activity assays}

The seedlings in the above-mentioned treatments were collected at $0,24,36,48,72,96$ and 120 hpi to examine the antioxidant enzymes activities. At each time point, two young leaves were collected from the upper parts of four seedlings (i.e., one sample), kept in liquid nitrogen during the sampling and then stored at $-80{ }^{\circ} \mathrm{C}$ until required. Leaf samples were collected from the control seedlings at each corresponding time point. The $\mathrm{H}_{2} \mathrm{O}_{2}$ content and the activities of SOD, CAT and POD were measured as described previously (Guo et al. 2012). The $\beta-1,3$-glucanase activity was measured by using laminarin as a substrate and assaying for D-glucose liberated by $\beta-1,3-$ glucanase (Souza et al. 2017). The PAL activity was measured using by using L-phenylalanine as a substrate and assaying for the amount of trans-cinnamic acid (TCA) generated by PAL (El-Shora 2002; Souza et al. 2017).

\section{Statistical analysis}

All data are expressed as the mean \pm standard deviation (SD) of four independent biological replicates $(n=4)$. The data from replicates of the four treatments (112-2-PM, 112-2CK, JJJD-PM and JJJD-CK) were subjected to two-way analysis of variance (ANOVA), and differences in the mean values between different treatments were determined using the least significant difference (LSD). Statistical procedures were performed using the statistical analysis system software DPS (v7.55, Hangzhou Ruifeng Inc., China). Values for $p \leq 0.05$ were considered as statistically significant.

\section{Results}

\section{Evaluation of PM resistance in C. moschata genotypes}

The severity of disease in the two PM pathogen-inoculated genotypes was visually appraised (Table 1). The disease index of in vivo leaves and in vitro leaf discs from the PMsusceptible JJJD genotype were 37.8 and 55.3, respectively.
Table 1 Disease index of pumpkin seedlings inoculated with powdery mildew

\begin{tabular}{lll}
\hline Genotype & \multicolumn{2}{l}{ Disease index } \\
\cline { 2 - 3 } & in vivo seedlings & in vitro leaf discs \\
\hline Inbred line "112-2" & $18.50 \pm 1.23$ & $26.67 \pm 2.35$ \\
cv "JJJD" & $37.80 \pm 2.41 *$ & $55.30 \pm 3.52 *$ \\
\hline
\end{tabular}

*indicates significant differences $(P<0.05)$

These values were significantly higher than those of the PMresistant 112-2 genotype at 6 dpi. Fungal growth was microscopically assessed at $0-120$ hpi (Fig. 1). No geminated $P$. xanthii conidia were detected for either of the genotypes at 0 hpi (Fig. 1a, g). On the leaf discs from the 112-2 seedlings, the $P$. xanthii conidia began to differentiate germtubes at $24 \mathrm{hpi}$, primary hyphae appeared at $48 \mathrm{hpi}$ and the hyphae bifurcated to form secondary hyphae at 72 hpi (Fig. 1b-d). However, on the leaf discs from the JJJD seedlings, hyphae were first detected at $24 \mathrm{hpi}$ and these bifurcated to form secondary hyphae at $48 \mathrm{hpi}$ and a dense hyphal network at 72 hpi (Fig. 1h-j). At 96 hpi, a relatively high number of hyphae and conidia maturing in chains were observed on the JJJD leaf discs and these were obviously more abundant than those detected on the 112-2 leaf discs (Fig. 1e, k). At 120 hpi, the conidia development of the fungus of the JJJD leaf discs also became more mature and dolioform (Fig. 1f, 1). Overall, the PM pathogens growth on the 112-2 genotype leaf discs was distinctly slower than that on the JJJD phenotype leaf discs as determined by both the visual estimates and microscopic observation. Together, these data suggest that there are differences in the responses to PM between the two genotypes that may be associated with different PM resistance mechanisms.

\section{Changes in the photosynthetic properties of pumpkin seedlings infected with PM}

The Pn, gs and Tr indices in both the 112-2-PM and JJJD-PM treatments were obviously reduced in comparison with the corresponding controls (Fig. 2a-c). These results suggest that stomatal closure is an effect of infection to stop the pathogen, which also leads to a reduction in the transpiration rate. The average Pn in the 112-2-PM and JJJD-PM treatments were significantly reduced, by $54 \%$ and $52 \%$, respectively, in comparison with the controls. In contrast, the $\mathrm{Ci}$ in both the 112-2PM and JJJD-PM treatments were increased in comparison with the controls (Fig. 2d). The above-mentioned indicators in leaves was not significantly different between both pumpkin genotypes infected with PM. The Pn of 112-2-PM was slightly higher than that of JJJD-PM after 4 dpi, and the gs of 

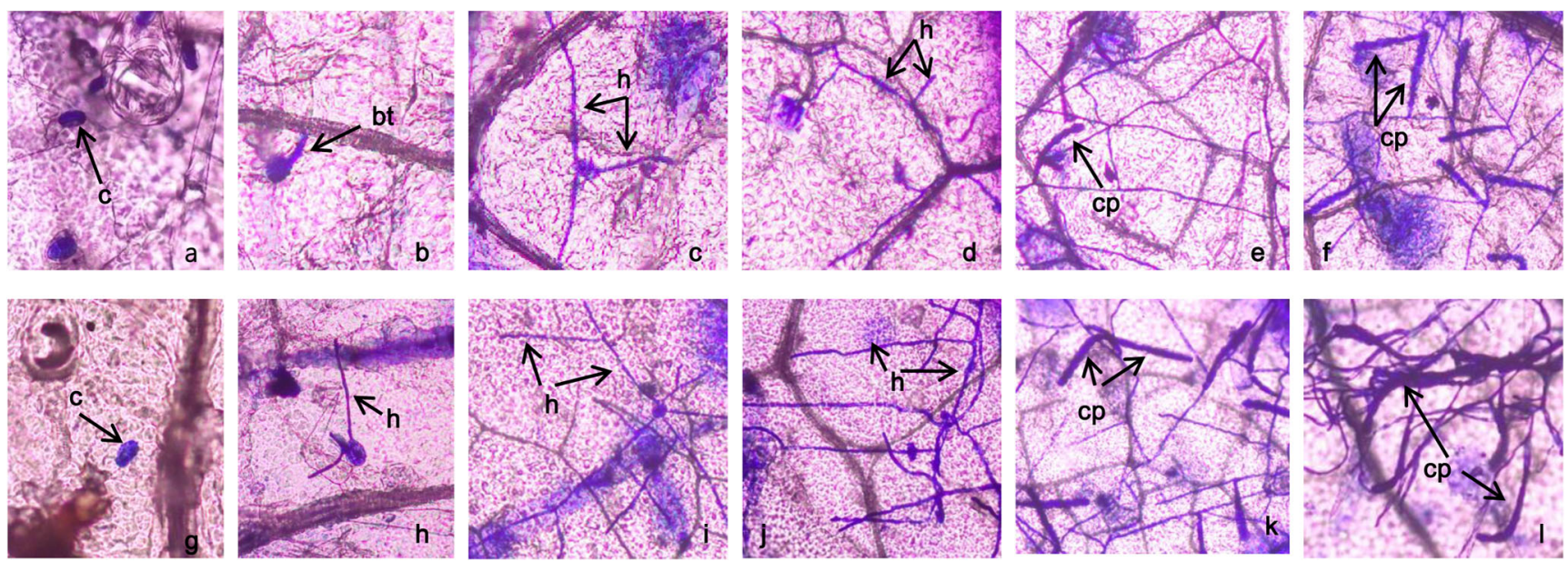

Fig. 1 Microscopic observation of Podosphaera xanthii infection in pumpkin seedlings. Powdery-mildew (PM)-inoculated leaves of genotype 112-2 at (a) $0 \mathrm{~h}, \mathbf{b} 24 \mathrm{~h}, \mathbf{c} 48 \mathrm{~h}, \mathbf{d} 72 \mathrm{~h}$, e $96 \mathrm{~h}$ and f $120 \mathrm{~h}$; and

PM-inoculated leaves of genotype JJJD at $\mathbf{g} 0 \mathrm{~h}, \mathbf{h} 24 \mathrm{~h}, \mathbf{i} 48 \mathrm{~h}, \mathbf{j} 72 \mathrm{~h}, \mathbf{k}$ $96 \mathrm{~h}$ and $1120 \mathrm{~h}$. The arrow indicates growth of the PM pathogen; h, hypha; c, P. xanthii conidium; gt, germtube; cp, conidiophore

112-2-PM was higher than that of JJJD-PM at different time points.

\section{Changes in the $\mathrm{H}_{2} \mathrm{O}_{2}$ contents and defense-related enzyme activities in pumpkin seedlings infected with PM}

The $\mathrm{H}_{2} \mathrm{O}_{2}$ contents and defense-related enzyme activities in pumpkin seedlings infected with PM were measured (Fig. 3). In the 112-2-PM treatment, the $\mathrm{H}_{2} \mathrm{O}_{2}$ content (except at $48 \mathrm{~h}$ ), SOD activity (except at $120 \mathrm{~h}$ ) and CAT activity (except at $120 \mathrm{~h}$ ) were reduced in comparison with the 112-2-CK control (Fig. $3 \mathrm{a}-\mathrm{c}$ ). The POD activity was increased in comparison with the control (Fig. 3d), suggesting that there is insufficient ROS accumulation in the 112-2-PM seedlings to activate this ROS-scavenging antioxidant enzyme. The $\mathrm{H}_{2} \mathrm{O}_{2}$ content (except at $72 \mathrm{~h}$ ) and the SOD activity in the JJJDPM treatment was reduced in comparison with the JJJD-CK control, while the CAT and POD activities were higher than the control (except at $36 \mathrm{~h}$ ). The CAT (except at $72 \mathrm{~h}$ ) and POD activities in the 112-2-PM treatment were lower than those of the JJJD-PM treatment throughout the infection process, suggesting that there is a negative correlation between those antioxidant enzyme activities and plant resistance to PM. The PAL activities in both the 112-2-PM (except at $36 \mathrm{~h}$ ) and JJJD-PM treatments were increased in comparison with their corresponding controls (Fig. 3e). While the $\beta-1,3-$ glucanase activities in both genotypes infected with PM were significantly decreased (Fig. 3f). These data suggest that PM induces PAL activity and inhibits $\beta$-1,3-glucanase activity in pumpkin seedlings. The PAL (after $48 \mathrm{~h}$ ) and $\beta$-1,3-glucanase activities in the 112-2-PM treatment were significantly higher than those of the JJJD-PM treatment, suggesting a positive correlation between the activities of these defense-related enzymes and plant resistance to PM.

\section{Discussion}

Disease symptoms, including foliar spots with intense chlorosis and necrosis with low development of hyphae were detected at $24 \mathrm{hpi}$, while maturation of $P$. xanthii conidia after 120 hpi shows that the whole infective process was completed during the $120 \mathrm{hpi}$. In contrast, the development of the fungal colonies was significantly reduced in the leaves of the PMresistant 112-2 seedlings at $120 \mathrm{hpi}$. The results suggest that the changes observed in the growth of the PM pathogen are closely related to the differences in PM resistance between the two genotypes.

Photosynthesis is the most important metabolic process in plants, in which light energy is converted to chemical energy (ATP), reducing power (NADPH), metabolic intermediates and organic compounds (Scharte et al. 2005). Inducing a reduction in photosynthesis may be one the primary strategies by which biotrophic pathogens establish a compatible interaction with their plant hosts (Bolton 2009). The average Pn was significantly reduced in the PM-inoculated seedlings, by $54 \%$ and $52 \%$ for the resistant and susceptible genotypes, respectively, in comparison with the controls. Moreover, the disease index at 6 dpi were 18.5 and 37.8 in the resistant and susceptible genotypes, respectively. Overall, the reductions in the $\mathrm{Pn}$ measured during the course of PM infection took place in parallel with reductions in the gs and the $\operatorname{Tr}$ The possible closure of stomata on leaves infected by PM may have contributed to these reductions. In addition, the $\mathrm{Ci}$ in both the 112-2-PM and JJJD-PM treatments were increased in comparison with their corresponding controls. This finding may be associated with the necrosis and chlorosis that often occurs as PM infection progresses, which abrogates the transport of water and solutes. This ultimately leads to stomatal closure and increases the $\mathrm{Ci}$ in the leaves of plants infected with PM and is associated with a reduction in the amount of green leaf tissue 

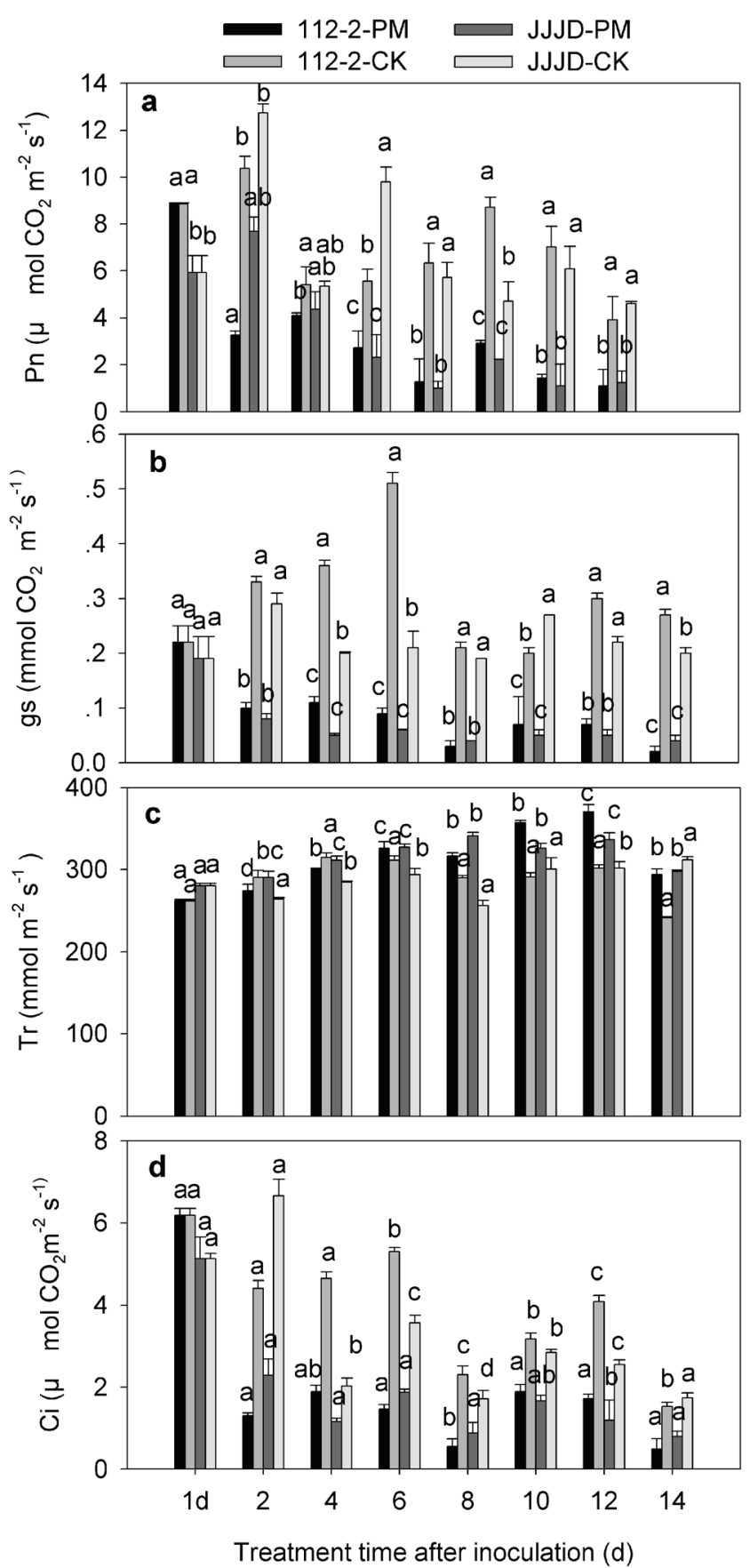

Fig. 2 Photosynthetic indices of pumpkin seedlings infected with Podosphaera xanthii. a Net photosynthetic rate (Pn), b stomatal conductance (gs), $\mathbf{c ~} \mathrm{CO}_{2}$ assimilation rate $(\mathrm{Ci})$, and $\mathbf{d}$ transpiration rate $(\mathrm{Tr})$ in the leaves of control (CK) and powdery mildew-infected (PM) pumpkin seedlings. The values are the means \pm SEs of four biological replicates. Data between treatments were analyzed by two-way ANOVA, and lowercase denotes statistical significance at $p \leq 0.05$

(Polanco et al. 2014; Tatagiba et al. 2016). The reduced photosynthesis in pathogen-infected leaves can occur due to changes in the opening and closure of stomata. This hinders $\mathrm{CO}_{2}$ diffusion in the mesophyll and can lead to reduction or destruction of chlorophylls or chloroplasts, which in turn results in chlorosis and necrosis of the leaf tissue (Rolfe and Scholes 2010).

In this study, the $\mathrm{H}_{2} \mathrm{O}_{2}$ contents in both the 112-2-PM (except at $48 \mathrm{~h}$ ) and JJJD-PM (except at $72 \mathrm{~h}$ ) treatments were reduced in comparison with the control. The SOD and POD activities were reduced and increased, respectively, in the seedlings after inoculation with PM. These data suggest that the reduction in the $\mathrm{H}_{2} \mathrm{O}_{2}$ content following $\mathrm{PM}$ inoculation in these plants was insufficient to activate these antioxidant enzymes to scavenge excess ROS. Taking into account the low $\mathrm{H}_{2} \mathrm{O}_{2}$ concentrations detected, we hypothesize that the crucial role of POD in the PM defense mechanism is its participation in the reinforcement of the cell wall through lignification, not its role as a $\mathrm{H}_{2} \mathrm{O}_{2}$-scavenging antioxidant enzyme. This hypothesis is supported by a similar report that suggested that POD plays an important role in host defense; in particular, through host tissue lignification (Rauyaree et al. 2001). The activities of CAT and POD in the PM-resistant seedlings were lower than those in the PM-susceptible seedlings during the infection process. These findings suggest that the activities of antioxidant enzymes are negatively correlated with pumpkin resistance to PM. Similar results were obtained in a previous study, which found that increased POD activity was correlated with resistance to downy mildew in cucumber (Ding et al. 2016). Among the enzymes that are involved in removing excess $\mathrm{H}_{2} \mathrm{O}_{2}$, CAT plays a key role (Mittler 2002). The reduced CAT activity in the PM-resistant genotype and the increased CAT activity in the PM-susceptible genotype may be associated with their different levels of resistance to PM. In general, it appears that reduced CAT activity increases host resistance to pathogen attack by maintaining a high $\mathrm{H}_{2} \mathrm{O}_{2}$ concentration (Magbanua et al. 2007).

PAL, a key enzyme of the general phenylpropanoid pathway, is involved directly or indirectly in the biosynthesis of phenolic compounds, phytoalexins, lignins and others secondary compounds. Increased PAL activity has been reported in plants that are resistant to virus infection (Siddique et al. 2014). These plants also have elevated levels of phenolics and lignin (Souza et al. 2017). Phenolic compounds are used by plants to generate the lignin precursors coumaryl, synapil and coniferyl. Plant cell wall lignification allows the formation of a physical barrier that prevents pathogens from spreading through the plant tissues (Ngadze et al. 2012). In our study, PAL activity was induced by PM treatment in both genotypes, and the PAL activity after 48 hpi in the 112-2PM treatment was distinctly higher than that of the JJJD-PM treatment. This shows that the PM resistance of pumpkin genotypes is positively correlated with their PAL activity and this correlation might be associated with lignin accumulation. Increased $\beta$-1,3-glucanase activity in virus-infected plants favors susceptibility to viruses and cell-to-cell movement of viruses via plasmodesmata (Iglesias and Meins 2000; Souza et al. 2017). Here, we found that both genotypes (112-2 and 


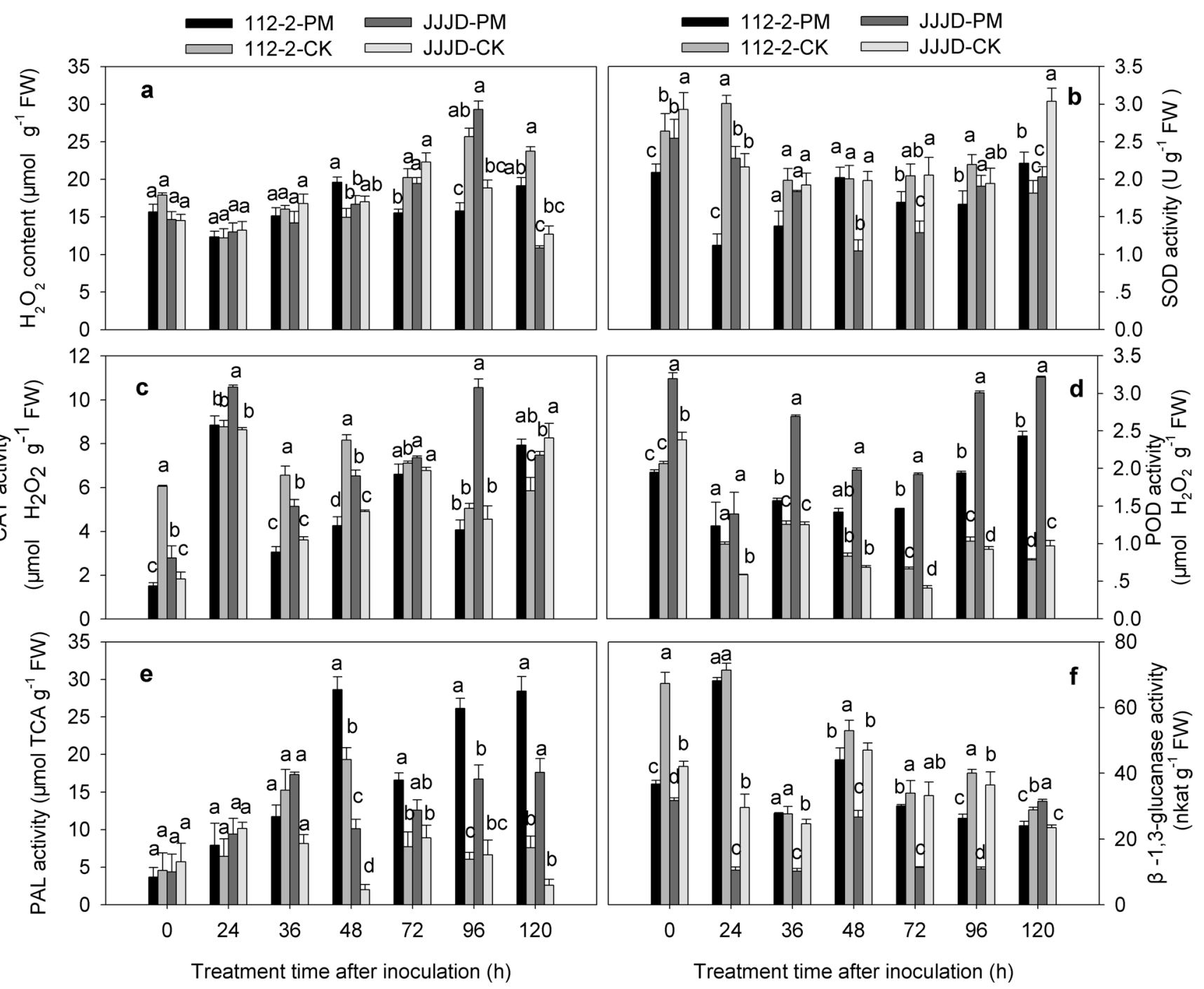

Fig. $3 \mathrm{H}_{2} \mathrm{O}_{2}$ contents and defense-related enzyme activities in pumpkin seedlings infected with Podosphaera xanthii. a $\mathrm{H}_{2} \mathrm{O}_{2}$ content and b superoxide dismutase (SOD), $\mathbf{c}$ catalase (CAT), $\mathbf{d}$ peroxidase (POD), e phenylalanine ammonia lyase (PAL) and $\mathbf{f} \beta$-1,3-glucanase activities in

the leaves of control (CK) and powdery-mildew-inoculated (PM) pumpkin seedlings. The values are the means \pm SEs of four biological replicates. Data between treatments were analyzed by two-way ANOVA, and lowercase denotes statistical significance at $p \leq 0.05$

JJJD) infectd with PM reduced $\beta$-1,3-glucanase activity, suggesting that reduced $\beta$-1,3-glucanase activity might contribute to $\mathrm{PM}$ resistance in pumpkin.

\section{Conclusions}

Powdery mildew is one of the most common fungal diseases in cucurbits and severely affects the plant growth and cucurbit yield. The results of this study indicate that $\mathrm{PM}$ resistance in pumpkin seedlings is associated with the maintenance of photosynthetic performance and the regulation of defense-related enzyme activities. Increased POD and PAL activities are probably vital for the pumpkin seedlings to restrict PM infection and systemic disease establishment. The data generated in this

study may provide the physiological mechanisms of PM resistance in pumpkin cultivars.

Acknowledgments $\mathrm{CBH}$ and GWL conceived the research and designed and conducted the experiments. LQF, LXZ and ZJG contributed new reagents and analytical tools. ZJG analyzed the data. GWL prepared the manuscript. All authors read and approved the manuscript.

Formatting of funding sources We acknowledge the following organizations for their financial support: National Natural Science Foundation of China (Grant No. 31401876) and Henan Province Focus on Research and Development and Promotion Special Project (Grant No. 182102110049).

\section{Compliance with ethical standards}

The authors declare that they have no conflict of interest. This research did not involve any human participants or animals. 
Open Access This article is licensed under a Creative Commons Attribution 4.0 International License, which permits use, sharing, adaptation, distribution and reproduction in any medium or format, as long as you give appropriate credit to the original author(s) and the source, provide a link to the Creative Commons licence, and indicate if changes were made. The images or other third party material in this article are included in the article's Creative Commons licence, unless indicated otherwise in a credit line to the material. If material is not included in the article's Creative Commons licence and your intended use is not permitted by statutory regulation or exceeds the permitted use, you will need to obtain permission directly from the copyright holder. To view a copy of this licence, visit http://creativecommons.org/licenses/by/4.0/.

\section{References}

Bassanezi RB, Amorim L, Bergamin-Filho A, Berger RD (2002) Gas exchange and emission of chlorophyll fluorescence during the monocycle of rust, angular leaf spot and anthracnose on bean leaves as a function of their trophic characteristics. J Phytopathol 150:3747

Behr M, Humbeck K, Hause G, Deising BD, Wirsel SGR (2010) The hemi biotroph Colletotrichum graminicola locally induces photosynthetically active green islands but globally accelerates senescence on aging maize leaves. Mol Plant-Microbe Interact 23:879892

Berger S, Sinha AK, Roitsch T (2007) Plant physiology meets phytopathology: plant primary metabolism and plant-pathogen interactions. J Exp Bot 58:4019-4026

Bolton MD (2009) Primary metabolism and plant defense-fuel for the fire. Mol Plant-Microbe Interact 22(5):487-497

Borden S, Higgins VJ (2002) Hydrogen peroxide plays a critical role in the defence response of tomato to Cladosporium fulvum. Physiol Mol Plant Pathol 61:227-236

Ding X, Jiang Y, Hao T et al (2016) Effects of heat shock on photosynthetic properties, antioxidant enzyme activity, and downy mildew of cucumber (Cucumis sativus L.). PLoS One 11(4):e0152429

El-Shora HM (2002) Properties of phenylalanine ammonia-lyase from marrow cotyledons. Plant Sci 162:1-7

Fukino N, Yoshioka Y, Sugiyama M, Sakata Y, Matsumoto S (2013) Identification and validation of powdery mildew (Podosphaera xanthii) resistant loci in recombinant inbred lines of cucumber (Cucumis sativus L.). Mol Breeding 32(2):267-277

Guo WL, Chen RG, Gong ZH et al (2012) Exogenous abscisic acid increases antioxidant enzymes and related gene expression in pepper (Capsicum annuum) leaves subjected to chilling stress. Genet Mol Res 11(4):4063

Guo WL, Chen BH, Chen XJ et al (2018) Transcriptome profiling of pumpkin (Cucurbita moschata Duch.) leaves infected with powdery mildew. PloS ONE 13(1):e0190175

Iglesias VA, Meins FJ (2000) Movement of plant viruses is delayed in a $\beta$-1,3-glucanase-deficient mutagenized showing a reduced plasmodesmatal size exclusion limit and enhanced callose deposition. Plant J 21:157-166

Iqbal MJ, Goodwin PH, Leonardos ED, Grodzinsli B (2012) Spatial and temporal changes in chlorophyll fluorescence images of Nicotiana benthamiana leaves following inoculation with Pseudomonas syringae pv. tabaci. Plant Pathol 61:1052-1062

Ishii H, Fraaije BA, Sugiyama T et al (2001) Occurrence and molecular characterization of Strobilurin resistance in cucumber powdery mildew and downy mildew. Phytopathology 91:1166-1171

Jones JDG, Dangl JL (2006) The plant immune system. Nature 444:323329
Kumudini S, Prior E, Omielan J, Tollenaar M (2008) Impact of Phakopsora pachyrhizi infection on soybean leaf photosynthesis and radiation absorption. Crop Sci 48:2343-2350

Lima ALS, DaMatta FM, Pinheiro HA, Totola MR, Loureiro ME (2002) Photochemical responses and oxidative stress in two clones of Coffea canephora under water deficit conditions. Environ Exp Bot 47:239-247

Magbanua ZV, Moraes CM, Brooks TD, Williams WP, Luthe DS (2007) Is catalase activity one of the factors associated with maize resistance to Aspergillus flavus? Mol Plant-Microbe Interact 20:697-706

Mittler R (2002) Oxidative stress, antioxidants and stress tolerance. Trends Plant Sci 7:405-410

Ngadze E, Icishahayo D, Coutinho TA, van der Waals JE (2012) Role of polyphenol oxidase, peroxidase, phenylalanine ammonialyase, chlorogenic acid, and total soluble phenols in resistance of potatoes to soft rot. Plant Dis 96:186-192

Perez-Garcia A, Romero D, Fernandez-Ortuno D et al (2009) The powdery mildew fungus Podosphaera fusca (synonym Podosphaera xanthii), a constant threat to cucurbits. Mol Plant Pathol 10:153-160

Polanco LR, Rodrigues FA, Nascimento KJT et al (2014) Photosynthetic gas exchange and antioxidative system in common bean plants infected by Colletotrichum lindemuthianum and supplied with silicon. Trop Plant Pathol 39(1):35-42

Rauyaree P, Choi W, Fang E, Blackmon B, Dean RA (2001) Genes expressed during early stages of rice infection with the rice blast fungus Magnaporthe grisea. Mol Plant Pathol 2(6):347-354

Rolfe SA, Scholes JD (2010) Chlorophyll fluorescence imaging of plant pathogen interactions. Protoplasma 247:163-175

Scandalios JG (2011) Wheat resistance to leaf blast mediated by silicon. Australas Plant Pathol 40:28-38

Scharte J, SchÖn H, Weis E (2005) Photosynthesis and carbohydrate metabolism in tobacco leaves during an incompatible interaction with Phytophthora nicotianae. Plant Cell Environ 28:1421-1435

Seung YY, Hwang BK (1996) Differential induction and accumulation of $\beta$-1,3-glucanase and chitinase isoforms in soybean hypocotyls and leaves after compatible and incompatible infection with Phytophthora megasperma f.sp.glycinea. Physiol Mol Plant Pathol 48:179-192

Siddique Z, Akhtar KP, Hameed A, Sarwar N, Khan SA (2014) Biochemical alterations in leaves of resistant and susceptible cotton genotypes infected systemically by cotton leaf curl Burewala virus. J Plant Interact 9:702-711

Souza PFN, Silva FDA, Carvalho FEL et al (2017) Photosynthetic and biochemical mechanisms of an ems-mutagenized cowpea associated with its resistance to cowpea severe mosaic virus. Plant Cell Rep 36: 219-234

Tatagiba SD, Neves FW, Bitti ALFE, Rodrigues FA (2016) Changes in gas exchange and antioxidant metabolism on rice leaves infected by Monographella albescens. Trop Plant Pathol 41:33-41

Thomas CE, Levi A, Caniglia E (2005) Evaluation of U.S. plant introductions of watermelon for resistance to powdery mildew. Hortscience A Publication of the American Society for Horticultural Science 40(1):154-156

Torres MA (2010) ROS in biotic interactions. Physiol Plant 138:414-429

Yadav M, Jain S, Tomar R, Prasad GBKS, Yadav H (2010) Medicinal and biological potential of pumpkin: an updated review. Nutr Res Rev 23:184-190

Zhou JG, Hu HL, Li XZ, Zhou RJ, Zhang HR (2010) Identification of a resource of powdery mildew resistance in Cucurbita moschata. Acta Hortic 871:141-146

Publisher's note Springer Nature remains neutral with regard to jurisdictional claims in published maps and institutional affiliations. 